\title{
Comment to Stephen Seligman
}

Anna Lisa Mazzoleni*

Re-reading and re-thinking Seligman's work is like exposing my own point of view rooted in relationship psychoanalysis to a different epistemic, methodological and theoretical approach, in order to gain new and deeper understanding. I am grateful to the author for numerous impressions, some of which I will treat in this work keeping at the forefront the concepts of subjectivity and intersubjectivity in clinical practice with children and their possible applications in adult psychology.

In particular, the author's proposition belongs to the debate between intersubjectivity and bi-personal psychoanalysis, introducing the following counterposed concepts: subjectivity/intersubjectivity, self-with-other/selfin-itself (pp 3), self which emphasizes autonomy/self which emphasizes interrelationships, two-person psychoanalysis/intersubjectivity ( $\mathrm{pp} 2$ ). The author believes that the constitution of self is a dynamic process, continuously being constructed and transformed, inseparable from the experiential context in which it finds itself. If this were not the case, it would mean emphasising autonomy as counterposed with interrelationships in a kind of stasis within the dyadic relationship (pp 7).

Secondly, Seligman discusses the parent-child relationship and the psychotherapist- patient relationship as though it were two distinct relationships, where growth takes place through alternation between the processes of construction and deconstruction, dissonance and recognition. From these statements, we can assume that the author's idea of good relationship is when even concepts of projective identification and empathy are portrayed as intersubjective constructions. If, on the one hand, I find Seligman's position ethical and respectful of human beings when he claims that neither parents nor therapists can tend towards a perfect model of relationship, or

\footnotetext{
*Psychologist-Psychotherapist, S.I.P.Re associate, 'children's area' member of the S.I.P.Re Institute in Milan. E-mail: mazzoleni.annalisa@gmail.com

${ }^{1}$ Thanks to Dr. Ottavia Zerbi, referent for the 'children's area', for her valuable contribution to the realization of this article
} 
empathy and identification, I think he assumes that human beings can handle and process possible non- identification or dissonances. On the other hand, if the relationship were characterized by an alternation between recognition and dissonance, inevitably, in my opinion, a model is intended.

This premise raises the following questions which constitute the underlying theme of this work: What is the epistemology of reference if we focus on the effect of the Other in the constitution of self, and assume a certain type of relationship as good? How can we think about the active part of the subject, and yet not exclude the incidence of context? In the light of which epistemic and theoretical perspective can we relate the psychotherapeutic process with the growth process of the child?

A psychological theory of the human being should explain how a human baby is born and evolves, why they suffer and enter crises. According to epistemology of complexity, generalization of the behavior of an observed system is not possible. The logic of understanding takes over from the mechanistic one of explanation, making way for description of subjective processes and global insights, as opposed to the sphere of logic, analytic, and the objective (Morin, 2007, pp 165). I find the theory of 'that I Subject' by Michele Minolli (2015) in line with this epistemology; a sort of general grid in which to place the process of the single I Subject in its uniqueness and subjectivity. Moreover, the ego-subject possesses the quality of 'the consciousness of consciousness' (Minolli, 2015), i.e., the awareness of the existence of consciousness in how it presents itself and appears at a given moment, and from which it is able to question itself, and to take note of how it is configured.

Maturana (Minolli, 2015, pp 80 et seq.) presents the theory that human beings enter a crisis when they are required to adapt to their context and find a new equilibrium while maintaining their unity and structure. Maturana also presents the image of the life path as a drifting boat, whose position in the sea depends on the boat and on its interaction with the waves and the wind, where inherent to its being in the sea the boat continuously shifts position from one place to the next, and that it is during these shifts that it encounters disturbances (Maturana, 1993, pp. 62).

My theory is, therefore, that each subject inevitably enters a crisis as an expression of that particular boat, in that sea and with those waves. Human beings may be considered the expression of those three aspects, which cannot be separated from one another, but to understand the suffering related to these disturbances it is important to understand the specifics of the boat, at a given moment in its journey. Therefore, if the focus is on the boat, preferential emphasis on the external may be ruled out, as is even the tending towards an idea of excessive autonomy.

Intersubjective theory arises in the field of parent / child relationship studies, and tends to interpret reality according to an interactive level of co- 
construction of the sea, the waves, and the boat. In this sense, it does not explain why the subject suffers and how to understand his suffering.

In this regard, Albasi argues that

\begin{abstract}
"psychoanalytic practice has become more interpersonal and intersubjective, since it has been undeniably influenced by attachment and Infant Research. (...). At the root of these changes in practice and in analytical research there is an even more marked trend, namely the growing parallelism between therapeutic and the development processes (Albasi et al., 2018, pp 254 - 255) (...), All these researchers are creating interconnected fields of research on what develops, what is interpersonal, and finally, how relational matrices become intrapsychic. There are many solid arguments that require and demand caution before an idea that could become too reductionist with regard to the undue interdisciplinary translations, even though the usefulness of these perspectives (as metaphors, epistemological perspectives and in clinical listening) appears, in my opinion, to be indisputable" (Harris, in Albasi et al., 2018, pp 50).
\end{abstract}

Finally, I would like to consider Green's harsh criticism of Stern in 2000 and in general of the theory of applying methods used in Infant Research to psychoanalytic research:

"The real object of psychoanalysis is not the child as we observe it, but the child in the adult (Dazzi et al., 2006, pp 723) (...) not taking these distinctions into account leads to confusing the instruments and methods and to trivializing the psychoanalysis of Infant Research" (Dazzi et al., 2006, pp 725).

Green occupies the role of defender of orthodox psychoanalysis, but I quote him to stimulate reflection on the concept of relationship as distinct from that of interaction. The interactionism of Infant Research represents a sort of photograph of the interactive regulation of two distinct systems which attempt to self-eco regulate. This fails to help the analyst understand the patient's suffering and what is happening on an implicit level in their relationship (Roggero et al., 2016).

Secondly, if the goal of psychoanalysis is to reach the level of consciousness of the consciousness of that particular I subject (Minolli, 2015), it is a very different end to the one of the child's growth process which is not necessarily aimed at returning to the self, or to the "consciousness of consciousness'. At the conclusion of the work I present a development theory which is, in my opinion, consistent with this approach.

In this section, we look at a case of adult psychotherapy where, interactively, the difficulty in managing silences, turns of speech, the processes of projective identification, transference and countertransference, recognition and dissociation, may be interpreted as an expression of the process of 'that' patient, and the implicit in the relationship. Ilaria is 40 years old and has been in psychotherapy with me for five years, once a week. During the sessions, she struggles to express herself verbally, she leaves a lot of space to 
me, in the silences she self-regulates her tension by getting up, changing her sitting position, rubbing her hands on her legs. She asks to always stay in touch via sms during the week. If I verbalize the least interpretation she gets angry and speaks aggressively, since everything I say she interprets as a further sign that she is incapable. Ilaria is very sensitive to dissonances, which for her are the confirmation that she cannot be loved. She arouses feelings of powerlessness and anger in me. If I were to see the dynamics of the relationship as a function of co-building an intersubjective balance, it would be impossible for me to appreciate the patient's progress and find a way to work through the stalemate. What we can do right away is appreciate the patient's projective identification, her need for recognition and her dissociation from her more fragile side, and work towards a balance between recognition and dissonance. Interestingly, through supervision, I am aware that the patient makes me feel important and the true composer of the analysis. This functions to cover my insecurity as a young analyst and the patient not facing the fear of standing on her own two feet rather than in the shadow of another, whom she controls by remaining dependent.

Similarly, as regards analytical work with children, I would argue that a photograph of what happens on an interactive level is insufficient for the analyst; the analyst needs to identify a developmental theory that involves understanding the child's development within its own immediate context.

I'll start with the assumption that Minolli (2015) makes explicit in his text: children function relative to how much the partners in a couple invest in them, and relative to a specific moment in the couple's life.

This is the case of a parenting couple, with a two-month-old girl. I was able to observe the case in a research project in publication. ${ }^{2}$ In this clinical vignette, I describe what may be defined as the investment of the parenting couple on the child. We will see what happens, interactively, between the child and her parents, and some theories which highlight how the child subjectively attempts to assimilate her parents' implicit investment. From the interview, it emerges that the couple bond is very centered on 'making a family', in the sense that this investment in the child serves to make the parents feel like able adults, independent of their respective families of origin. It also serves to cover the real fragile role of 'child' which emerges in both parents. The mother, who comes from a totally feminine world, would not have tolerated the arrival of a male child, and she explicitly expresses a sense of guilt for having needed the ventouse during childbirth. The father tends to agree on the whole with the mother's opinions, but is detached from the affair and the experiences related to childbirth; he relates little

\footnotetext{
${ }^{2}$ Research carried out as a member of the Centro Nazionale Studi e Ricerche S.I.P.Re, in collaboration with the Mangiagalli Clinic in Milan.
} 
about his personal history, seemingly considering it unimportant. As for their expectations of the child, both already imagine her as a teenager. For the mother, the child should not be too transgressive, whereas the father would prefer his daughter not to grow up at all.

From an observation of the interactions carried out using Lynne Murray's Global Rating Scale, it emerges that both the father and the mother are very demanding of the child, the mother seems physically intrusive and the father seems distant. The child holds up better in interaction with the father, while she appears more irritated in interaction with the mother. Episodes of pleasure and play are almost absent in interaction with the mother. Although these episodes are more frequent with the father, they lack peaks of excitement and arousal. In couple-child interaction, the father takes a back seat with respect to the mother, and awaits authorization to become active, to enter into contact with the child. Even during interaction with the parenting couple, the child shows restlessness and agitation.

This father's submissiveness suggests he is avoiding facing the fear of being seen as an active subject, which also serves to keep the mother, who is unable to face her own fragility, in a position of apparent strength and autonomy.

The child seems to be able to express impatience at the demands and expectations of both parents by protesting, though not excessively, and by not showing peaks of positive involvement. The child's solutions may be read as an expression of the implicit in her immediate context in an attempt to maintain her own internal consistency. Possible analytical interventions could aim at helping the parents understand the implications of their investment in the child by noticing the spontaneous ways in which their child adapts and relaunches the relationship, at discovering new ways of being parents and together identifying a new and unexpected stability.

\section{REFERENCES}

Albasi, C., \& Barsness R.E. (2018). Competenze cliniche nella psicoanalisi relazionale. Un manuale per la pratica, lo studio, la ricerca. Giovanni Fioriti Editore.

Brandt, K., Perry, B.D., Seligman, S., \& Tronick E. (2014). Infant and Early Childhood Mental Health. Core Concepts and Clinical Practice. Washington DC, London, England, American Psychiatric Publishing.

Dazzi, N., Lingiardi, V., Colli, A. (2006). La ricerca in psicoterapia. Modelli e strumenti. Milano, Cortina.

Gill, M. (1994). Psicoanalisi in transizione. Milano, Cortina.

Green, A. (2000). Scienza e fantascienza nella ricerca sull'infanzia. In V. Bonaminio e P. Fabozzi (a cura di) Quale Ricerca per la Psicoanalisi? Milano, Franco Angeli, 2002.

Maturana, H.R. (1993). Autocoscienza e realtà. Raffaello Cortina Editore.

Minolli, M. (2009). Psicoanalisi della relazione. Franco Angeli.

Minolli, M. (2015). Essere e divenire. La sofferenza dell'individualismo. Franco Angeli.

Mitchell, S.A. (1993). Gli orientamenti relazionali in psicoanalisi. Per un modello integrato. Bollati Boringhieri. 
Morin, E. (2007). Il metodo 3. La conoscenza della conoscenza. Raffaello Cortina Editore. Roggero, M.P., \& Minolli M. (2016). Un dibattito dialogico su Cavelzani e il saggio di Tronick: la ricerca e la pratica clinica possono intrecciarsi fruttuosamente? Psychoanal Dialogues, 26,5.

Stern, D.B. (2007). L'esperienza non formulata. Dalla dissociazione all'immaginazione in psicoanalisi. Edizioni Del Cerro.

The Boston Change Process Study Group (2012). Il cambiamento in psicoterapia. Raffaello Cortina Editore.

Conflict of interest: the authors declare no potential conflict of interests.

Ethics approval and consent to participate: the manuscript does not contain any elements that would allow the recognition of the patient.

Received for publication: 19 March 2020.

Accepted for publication: 19 March 2020.

${ }^{\circ}$ Copyright: the Author(s), 2020

Licensee PAGEPress, Italy

Ricerca Psicoanalitica 2020; XXXI:275

doi:10.4081/rp.2020.275

This article is distributed under the terms of the Creative Commons Attribution

Noncommercial License (by-nc 4.0) which permits any noncommercial use, distribution,

and reproduction in any medium, provided the original author(s) and source are credited. 